\title{
OUTCOMES WITH INTRA-AORTIC BALLOON PUMP IN HIGH RISK CARDIAC SURGERY PATIENTS
}

\author{
Ihab M Y Moursi MD. Karim Al Fakharany MD. \\ Department of Cardiac surgery, Zagazig University Hospital, Faculty of Human Medicine [EGYPT].
}

\begin{abstract}
Introduction:In high-risk cardiac surgical patients the intra-aortic balloon pump (IABP) is the most frequent used tool for temporary mechanical circulatory support during the perioperative phase. The effects of IABP are an increase in diastolic blood pressure, an improvement in coronary perfusion and a reduction of ventricular afterload, so it increases the stroke volume and cardiac output.

Objective:To study the effect of preoperative use of intra-aortic balloon pump (IABP) on the outcome of high-risk patients that were subjected to coronary artery bypass graft (CABG) surgery.

Methods: From June 2009 to June 2011. Group of 100 patients considered as high-risk patients were subjected to elective bypass cardiac surgery at our center.

Forty patients subjected to preoperative IABP as a prophylactic measure and 60 patients were not subjected to IABP. This is retrospective study of prospectively collected data. The definition of High risk was the presence of two or more known risk factors. The patient's outcome is compared regarding the predicted mortality of the Euro SCORE. The preoperative effect of IABP on the outcome, mortality and 30 days follow-up was statistically analyzed.

Results:Forty patients subjected to preoperative IABP as prophylactic measure due to higher Euro SCORE-predicted mortality than other 60 patients did not subject to IABP(60\% vs $40 \%$,

$\mathrm{P}=<0.05)$. Seventy patients $(70 \%)$ were male while $(30 \%)$ were female with a mean age of $58.62 \pm$ 9.65 years. Patients subjected to preoperative IABP had increased a percentage of hospital mortality (P $=<0.05)$ but this percentage is relatively lower than predicted by Euro SCORE. Patients subjected to preoperative IABP had lower rate of postoperative complication (acute kidney insult $(\mathrm{P}=0.045)$, cardiac surgical intensive care unit $(\mathrm{CSICU})$ stay $(\mathrm{P}=0.032)$ and decrease the need for postoperative inotrope $(\mathrm{P}=0.046)$ ) compared to patients without preoperative IABP use. Other complications postoperative were low and similar in both groups.
\end{abstract}

Conclusions:

We conclude that patients have high-risk CABG, the preoperative IABP in this group with higher predicted mortality was associated with a relative reduction than predicted by Euro score.

The preoperative IABP in this group has a reliable and acceptable outcome on postoperative complications.

Keywords: intra-aortic balloon pump, High Risk, Cardiac Surgery

Corresponding author: Karim Al Fakharany

Email:ihabmoursi@hotmail.com.

\section{INTRODUCTION}

I ntra-aortic balloon pumping (IABP) is a well-established mechanical support device for temporary ventricular assistance in the treatment of the failing heart (1).Intra-aortic balloon pumping augment myocardial oxygen supply and decreases myocardial oxygen demand by the mechanical effect of the balloon. It increased diastolic perfusion of the coronary arteries. For more than 30 years it has been used for critically ill cardiac patients. The effectiveness of intra-aortic balloon pump in the preoperative period for high-risk coronary artery bypass grafting patients was suggested in literature (2). Positive preoperative benefits of this technology may yield good outcomes due to its hemodynamic effect, minimize the length of intensive care unit and the hospital stay and decrease the complications. To avoid the complications related to the intra-aortic balloon 
pump, it is essential to have a profound understanding of proper mechanism and function and an excellent critical care management by the nursing team. So it can reduce morbidity, mortality, and intensive care unit stay and hospital expenses as reported. (34).

Many deaths during the perioperative period are linked to low cardiac output (5). Due to the advance in interventional cardiology for coronary artery disease, it leads a small number of patients treated with surgery. These surgical patients have a relatively high-risk profile including poor left ventricular function. The American Heart Association/American College of Cardiology declares coronary artery bypass grafting (CABG) a class I recommendation in patients with symptomatic coronary artery disease with left ventricular dysfunction (6). The incidence of operative mortality is high in patients with poor left ventricular function than in patients with a normal or a moderately dysfunctional heart (7). Well known high-risk factors for mortality and major postoperative morbidity are the poor left ventricular function (ejection fraction $<40 \%$ ), diffuse coronary artery disease, left main stem stenosis $>70 \%$ and unstable angina at the time of operation despite optimal medical treatment. The effective timing for preoperative IABP treatment has not been clearly established, There is debated studies have shown that the use of preoperative IABP in patients with severe left ventricular dysfunction undergoing CABG does not lead to improved outcomes in terms of the mortality and major complications (8).The results of preoperative use of IABP in cases with unstable hemodynamics is well examined, but there are limited studies about the preoperative use of IABP in stable cases with poor left ventricular function. Our objective isto study the effect of preoperative use of intra-aortic balloon pump (IABP) on the outcome of high-risk patients subjected to coronary artery bypass graft (CABG) surgery with low ejection fraction $\leq 35 \%$ and compare the observed mortality and the predicted mortality by Euro SCOREII.

\section{PATIENTS AND METHODS}

This is a retrospective study of prospectively collected data according to the ethics of hospital scientific committee authorization with individual patients consent. From June 2009 to June 2011. Group of 100 patients considered as high-risk patients were subjected to elective bypass cardiac surgery at our cardiac center. Forty patients subjected to preoperative IABP as a prophylactic measure (Group 1), and 60 patients did not subject to IABP (Group 2). The definition of the high risk was the presence of two or more known risk factors. Patients having an ejection fraction $\leq 35 \%$, determined by conventional two-dimensional echocardiogram or preoperative ventriculography, were included in this study, unstable angina at the time of operation despite optimal medical treatment, the left main disease at least $70 \%$ stenosis . Preoperative insertion of a SwanGanz catheter for all patients to measure the cardiac performance, cardiac index (L/m2 per minute), calculated from cardiac output data. It is measured intra-operatively and at least 48 hours postoperatively. The exclusion criteria in our study are emergency operation, patients with hemodynamic instability, associated valve surgery, patients with ischemic mitral regurgitation more than grade 2 and patients with poorly controlled preoperative ventricular arrhythmias. Preoperative, intraoperative, and postoperative patient's variables were registered. The effect of preoperative IABP on patient's outcome, mortality, and 30 days follow-up was statistically analyzed. The observed mortality compared to the predicted mortality of the Euro Score II. Hospital mortality was defined as deathafter the procedure before patient's discharge regardlessof the duration of hospitalization. Patients who died afterdischarge from hospital but within 30 days after the procedurewere also considered as hospital mortality. Renal complications included acuterenal failure needs hemodialysis with creatinine more than 200 $\mathrm{mmol} / \mathrm{L}$. Neurological complications were defined as transient or persistent postoperative neurological dysfunction that was confirmed by 
computer tomography or nuclear magnetic resonance imaging.

The intra-aortic balloon pumps for group1:

IABP was inserted in the intensive care unit by modified Seldinger technique in all patientsthrough the right femoral artery during 24 hours preoperatively. It was $8 \mathrm{~F} 40 \mathrm{cc}$ balloon Rediguard $\AA$ IAB Catheter (Datascope Corp, Fairfield, New Jersy) connected to a Datascope pump (Datascope, Fairfield, NJ. USA). All patients were anti-coagulated with heparin IV, to keep an activated partial thromboplastin time (APPT) 1.5-2 times the normal value. The IABP support was terminated when hemodynamic stability was restored (maintaining a cardiac index 2.0 $1 / \mathrm{min} / \mathrm{m} 2$ with minimal pharmacologic support). An Echocardiogram should be performed to evaluate the ejection fraction, global and regional wall contractility, before terminating the IABP. All measurements of cardiac output should be recorded for postoperative 48 hours.

\section{Surgical Techniques:}

All patients were operated through a median sternotomy. Anesthesia, cardiopulmonary bypass (CPB) and surgical techniques were standardized. Conventional techniques used for myocardial revascularization. Myocardial protection was achieved by cold blood intermittent cardioplegia solution which was infused into the aortic root, with topical hypothermia $\left(28-32^{\circ} \mathrm{C}\right)$. The internal thoracic artery was used as a pediculate graft for revascularization of the LAD. Other graft conduits in this study were venous grafts.

\section{Data Analysis:}

SPSS (SPSS Version 16.0. Chicago, SPSS Inc.), it is used for statistical analysis. Quantitative variable were presented as mean \pm $\mathrm{SD}$ and qualitative variables was presented as frequency and percentages. The independent sample t-test was applied for comparison of the quantitative data. For qualitative data, the $\chi 2$ - test was used. A P-value of 0.05 or less was accepted as significant.

\section{RESULTS}

A group of 100 patients considered as high-risk patients with left ventricular ejection fraction $\leq$ $35 \%$ were subjected to CABG with cardiopulmonary bypass (CPB).Patients were divided into two groups: group I included patients in whom preoperative prophylactic IABP was used $(n=40)$, whereas group II included patients who did not receive preoperative IABP $(n=60)$.

Out of 100 patients, $64(64 \%)$ were male, whereas $36(36 \%)$ were female. The mean age of the patients was $56.52 \pm 9.74$ years.

Table 1. Showsthe Clinical and demographic patient's data in both the groups, there is no significant statistical difference in all data except that NYHA III or IV dyspnea was presented more in group 1. Also, there was more female sex presentation in group1. It shows the operative patient's data with no significant difference concerning Cross-clamp time (min), Number of grafts (mean, S.D.) and bypass time although there is a higher value in group 2 than group1. Table 1 shows also the Post-Operative patient's data with significant differences including that the post-operative renal insult (5\% vs $15 \%, \mathrm{p}$ value $=0.048)$, inotropic use $(12.5 \%$ vs $20 \%$, p-value $=0.047)$, ICU stay/days $(4.80 \pm 2.2$ vs $8.67 \pm 2.8$, p value $0.032)$ and hospital stay/days $(8.8 \pm 0.5$ vs $13.7 \pm 0.4$, p-value $<0.0001$ ) were less in group 1 related to group2. The cardiac index was significantly improved (p-value <0.0001) in group1 than in group 2. Table 1 shows that Group 1 had significant in-hospital mortality rate $(12.5 \%$ vs $6.7 \%$ with $\mathrm{P}$-value 0.002$)$. Table 2 shows that despite the significant incidence of hospital mortality in group 1 more than group 2, there is more significant difference ( $p$-value $<0.001)$ between the observed and the predicted mortality concerning group 1 than group 2 . 
Table I: Clinical and Demographic Patient's Data

\begin{tabular}{|c|c|c|c|}
\hline Data & $\begin{array}{l}\operatorname{IABP}(\mathbf{n}=40) \\
(\operatorname{group~I})[\mathbf{N}(\%)]\end{array}$ & $\begin{array}{l}\text { No }- \text { IABP }(\mathbf{n}=\mathbf{6 0}) \\
(\text { group II) }[\mathbf{N}(\%)]\end{array}$ & P-value \\
\hline Sex & & & \\
\hline Male & $15(37.5 \%)$ & $48(80 \%)$ & $\mathbf{S}$ \\
\hline Female & $25(62.5 \%)$ & $12(20 \%)$ & $(0.001 *)$ \\
\hline Age (years) & $56.6 \pm 8.7$ & $53.53 \pm 10.6$ & NS \\
\hline Hypertension & $21(52.5 \%)$ & $22(36.7 \%)$ & NS \\
\hline Diabetes & $16(40 \%)$ & $29(48.3 \%)$ & NS \\
\hline Preoperative LVEF & $33.7 \pm 11.5$ & $39.5 \pm 10.6$ & $\begin{array}{l}S \\
\left(0.005^{*}\right)\end{array}$ \\
\hline $\begin{array}{l}\text { Preoperative } \\
\text { creatinine }\end{array}$ & $1.3 \pm 1.1$ & $1.2 \pm 0.6$ & NS \\
\hline $\begin{array}{l}\text { NYHA class III or } \\
\text { IV }\end{array}$ & $20(50 \%)$ & $21(35 \%)$ & $\begin{array}{l}\mathbf{S} \\
(0.023 *)\end{array}$ \\
\hline history of IHD & $16(40 \%)$ & $20(33.3 \%)$ & NS \\
\hline Hyperlipidemia & $6(15 \%)$ & $8(13.3 \%)$ & NS \\
\hline $\begin{array}{l}\text { Euro SCOREII } \\
\text { (mean, S.D.) }\end{array}$ & $7.5 \pm 3.5$ & $7.1 \pm 3.2$ & NS \\
\hline Bypass time (min) & $80.00 \pm 19.93$ & $86.13 \pm 30.92$ & NS \\
\hline $\begin{array}{l}\text { Cross-clamp time } \\
\text { (min) }\end{array}$ & $42.12 \pm 5.65$ & $48.03 \pm 15.44$ & NS \\
\hline
\end{tabular}

\begin{tabular}{|c|c|c|c|}
\hline $\begin{array}{l}\text { Number of grafts } \\
\text { (mean, S.D.) }\end{array}$ & $3 \pm 0.7$ & $3 \pm 0.8$ & NS \\
\hline $\begin{array}{l}\text { Post-operative renal } \\
\text { insult }\end{array}$ & $2(5 \%)$ & $9(15 \%)$ & $\begin{array}{l}\mathrm{S} \\
0.048^{*}\end{array}$ \\
\hline $\begin{array}{l}\text { inotropic } \\
\text { support } \\
\text { more than } 3 \text { days }\end{array}$ & $5(12.5 \%)$ & $12(20 \%)$ & $\begin{array}{l}\text { S } \\
0.047 *\end{array}$ \\
\hline $\begin{array}{l}\begin{array}{l}\text { Ventilation } \\
\text { (hours) }\end{array} \\
\end{array}$ & $17.8 \pm 3.9$ & $28.2 \pm 7.7$ & NS \\
\hline Stroke & $2(5 \%)$ & $3(5 \%)$ & NS \\
\hline ICU stay (days) & $4.80 \pm 2.2$ & $8.67 \pm 2.8$ & $\begin{array}{l}\mathrm{S} \\
0.032 * \\
\end{array}$ \\
\hline Hospital stay (days) & $8.8 \pm 0.5$ & $13.7 \pm 0.4$ & S<0.0001* \\
\hline CI (cardiac index) & $3.3 \pm 0.05$ & $2.6 \pm 0.07$ & $\mathrm{~S}<0.0001^{*}$ \\
\hline $\begin{array}{l}\text { In-hospital } \\
\text { Mortality }\end{array}$ & $5(12.5 \%)$ & $4(6.7 \%)$ & $\mathrm{S}(0.002) *$ \\
\hline
\end{tabular}

IABP: intra-aortic balloon pump; NYHA: New York Heart Association; IHD: ischemic heart disease, LVEF: Left Ventricular Ejection Fraction. SD: Standard deviation NS. Non-significant, *S.significant $\leq 0.05$ 
Table II

Comparison of the observed and predicted mortality

\begin{tabular}{|c|c|c|c|}
\hline Groups & N (\%) Observed & N (\%) predicted & P Value \\
\hline All patients 100 & $9 \quad(9 \%)$ & $20(20 \%)$ & $<0.05$ \\
\hline Group $1 \quad 40$ & $5 \quad(12.5 \%)$ & $17(42.5 \%)$ & $<0.001$ \\
\hline Group 260 & $4 \quad(6.7 \%)$ & $11(18.3 \%)$ & $<0.05$ \\
\hline
\end{tabular}

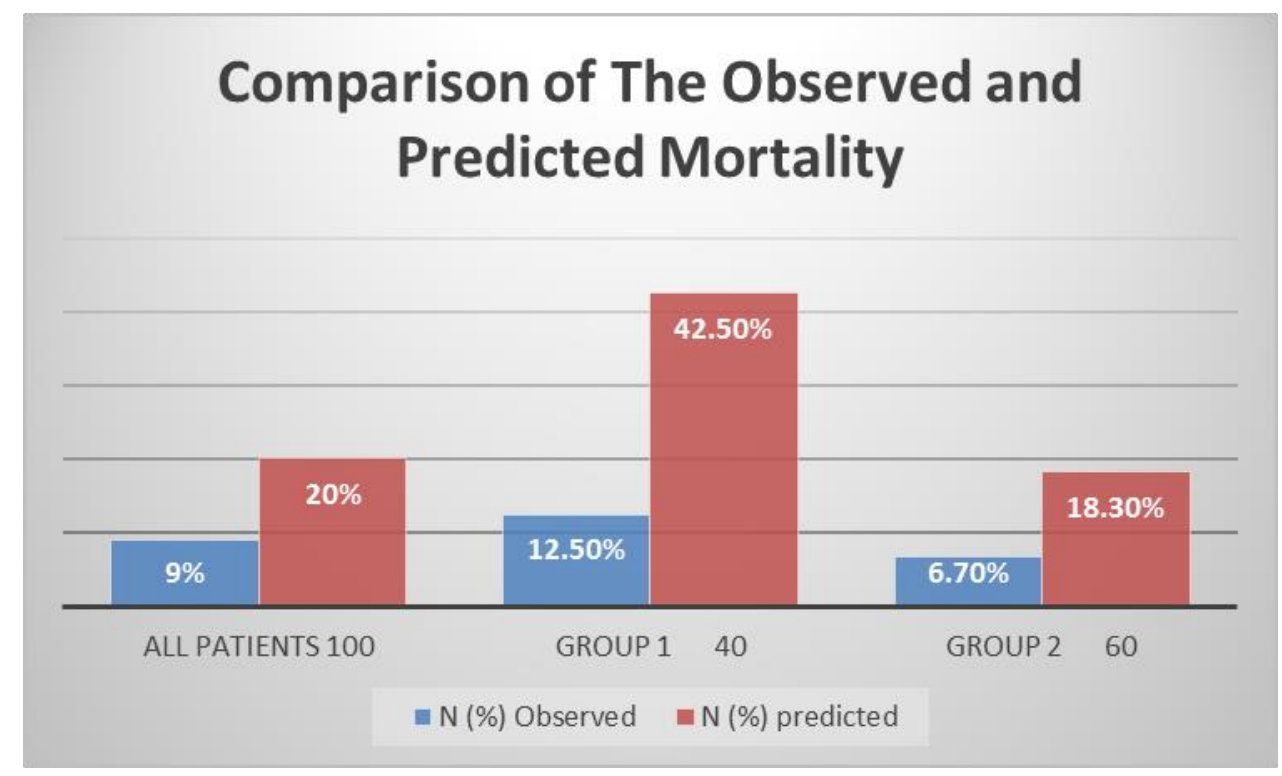

Figure 1: Comparison of the observed and predicted mortality

\section{DISCUSSION}

IABP support has beneficial anti-ischemic and hemodynamic effect. In non-elective CABG operation with low ejection fraction, NYHA class III-IV symptoms and re-operation, there is agreement about the use of IABP (9). However, there is some debate about its effect on high-risk hemodynamically stable patients. Our study shows that high-risk stable patients with severe left ventricular dysfunction subjected to $\mathrm{CABG}$, managed with preoperative insertion of IABP during 24 hours before operation, have lower incidence of morbidity, concerning postoperative, renal insult, inotropic support, a shorter ICU, and hospital stay. Christenson et al, (4) demonstrate that the use of IABP as a prophylactic measure play an important role for better performance of cardiac muscle. Our study did not revealed a significant reduction in mortality incidence in a group where IABP was applied. Davoodi et al. (10) revealed that the preoperative use of IABP in patients with severe left ventricular dysfunction can lead to increase the incidence of mortalityand morbidity.Our results coincide with Aksnes et al. (11) study that revealed a high mortality rate in patients receiving IABP in comparison with patients without IABP.

Christenson et al. (12, 13) revealed that preoperative use of IABP in high-risk patients can shorten the length of hospital stay and lowers postoperative mortality and morbidity. In Cochrane Database of Systematic Reviews that recently analyzed in a meta-analysis by Field et al. (14), who revealed a significant beneficial effect of preoperative IABP concerning the in-hospital mortality and low postoperative cardiac index. All these studies have a problem of a small population design and the question of debate between the 
prophylactic and the therapeutic purpose of preoperative insertion of IABP. The metaanalysis study suggested that preoperative insertion of IABP decrease the mortality in elective high-risk patients subjected to coronary artery bypass graft (CABG).(15,16,17). The discrepancy in the meta-analysis study (16) may be due to that patients using IABP have a risk of increased mortality because of other factors. This coincides with our results where patients with NYHA III or IV dyspnea received IABP, they represent a high-risk profile. So, these patients had a high mortality compared to asymptomatic patients. The high-risk patients' definition is unclear so we cannot know precisely who will benefit by insertion of IABP (16), this context needs Propensity scorematched studies.On the other hand some authors' revealed ineffectiveness of preoperative IABP insertion with a higher inhospital mortality (11).Holman et al. did not reveal a survival advantage from the use of a prophylactic IABP compared to risk-matched patients control. He revealed a shorter hospital stay post-CABG (18) after exclusion of many factors including emergency operation, recent myocardial infarction and patient with hemodynamic instability. Preoperative IABP insertion decrease hospital mortality compared with predicted Euro SCORE mortality (19).Our patients subjected to $\mathrm{CABG}$ with preoperative IABP insertion had no complication related to IABP. Concerning the preoperative insertion timing, it was inserted within 24 before the procedure that is coincide with the opinion of Christenson and colleagues (4). The incidence of post-operativerenal insultafter coronary artery bypass is $13 \%$ (20) which is predisposed by preoperative low ejection fraction (21).our study revealed that the preoperative use of IABP decreases the postoperative renal insult. This can be explained by improvement in cardiac output and renal flow that coincide with authors $(22,23)$. Our study revealed that the use of preoperative IABP reduces the use of inotropic support and intensive care unit (ICU) stay and this can be explained by the effect of IABP that improves cardiac output and diastolic pressure which increase coronary blood flow with reduction of the afterload this circle leads to improvement of ejection fraction of the heart, cardiac performance, and cardiac index. This coincides with the data of arandomized metaanalysis control trials about the use of IABP in high-risk patients (24).studies revealed that Preoperative IABP in patients with low ejection fraction of $24.6 \%$ can be increased to $33.2 \%$ after coronary artery bypass graft $(25,26)$. This increase is not only of statistical significance but also of clinical and physiological improvement with the consequence effect of decrease incidence of morbidity and reduces hospital and ICU stay irrelevant to the IABP related complications that can increase ICU stay (24).Our study confirmed that IABP significantly reduces the length of stay in the ICU. This coincides with the report of propensity score-matched study by Micelli et al. (27).

\section{LIMITATIONS}

We have a limitation in this study the first, it is a retrospective study with a small number of cases and a short period of follow-up. The second one is that the decision of insertion of IABP depends on the working surgeon. The third element is that the unclear definition of high-risk patient. All these factors lead to some bias can affect our results and limit the accurate application of propensity score. We advise more randomized study to clarify this subject.

\section{CONCLUSION}

This study conclude that patients have highrisk $\mathrm{CABG}$ with a low ejection fraction, the preoperative use of IABP in this group with higher predicted mortality was associated with a relative reduction than predicted by Euro score. The preoperative IABP in this group has a reliable and acceptable outcome on postoperative complications.

\section{REFERENCES}

1. C Diez, et al. Euro SCORE directed IABP placement in high-risk patients undergoing cardiac surgery. ICVTS 2008;7:389-395

2. Rocha Ferreira GS, de Almeida JP, Landoni $\mathrm{G}$, et al. Effect of a Perioperative Intra-Aortic Balloon Pump in High-Risk Cardiac Surgery Patients: A Randomized Clinical Trial. Crit 
Care Med. 2018 Apr 30. doi: 10.1097/CCM.0000000000003185.

3. Dietl CA, Berkheimer MD, Woods EL, Gibert CL, Pharr WF, Benoit CH. Efficacy and cost-effectiveness of preoperative IABP in patients with ejection fraction of 0.25 or less. Ann Thorac Surg 1996; 62: 401-09.

4. Christenson JT, Somonet F, Badel P, Schmuzger M. Optimal timing of preoperative intraaortic balloon pump support in high risk coronary patients. Ann Thorac Surg 1999; 68: 934-39.

5. Baskett RJ, Ghali WA, Maitland A, Hirsch GM. The intraaortic balloon pump in cardiac surgery. Ann Thorac Surg. 2002; 74(4):127687.

6. Hillis LD, Smith PK, Anderson JL, Bittl JA, Bridges CR, Byrne JG, et al. ACCF/AHA guideline for coronary artery bypass graft surgery. Circulation 2011; 124:e652-e735.

7. Hamad SMA, Tan ME, van Straten AH, van Zundert AA, Schhönberger JP. Long-term results of coronary artery bypass grafting in patients with left ventricular dysfunction. Ann Thorac Surg 2008; 85:488-493.

8. Ranucci M, Castelvecchio S, Biondi A, de Vincentiis C, Ballotta A, Varrica A, et al. Surgical and Clinical Outcome Research (SCORE) Group A randomized controlled trial of preoperative intra-aortic balloon pump in coronary patients with poor left ventricular function undergoing coronary artery bypass surgery. Crit Care Med 2013; 41:2476-2483

9. Baskett RJF, Ghali WA, Maitland A, Hirsch GM. The intraaortic balloon pump in cardiac surgery. Ann Thorac Surg 2002; 74:12761287

10. Davoodi S, Karimi A, Ahmadi SH, Marzban M, Movahhedi N, Abbasi K, et al. Coronary artery bypass grafting in patients with low ejection fraction: the effect of intra-aortic balloon pump insertion on early outcome. Indian J Med Sci 2008; 62:314-322.

11. Aksnes J, Abdelnoor M, Platou ES, Fjeld NB. Mortality in patients supported by intra-aortic balloon pump in the course of cardiac surgery was related to perioperative myocardial infarction. Eur J Cardiothorac Surg 1996; 10:408-411.

12. Christenson JT, Simonet F, Badel P, Schmuziger M. Evaluation of preoperative intra-aortic balloon pump support in high- riskcoronarypatients. Eur J Cardio-Thorac Surg 1997; 11:1097-1103.

13. Christenson JT, Schmuziger M,SimonetF.Effectivesurgicalmanagement of high-risk coronary patients using preoperative intra-aortic balloon counterpulsation therapy. Card Surg 2001; 9:383-390

14. Field ML, Rengarajan A, Khan O, Spyt T, Richens D. Preoperative intra-aortic balloon pumps in patients undergoing coronary artery bypass grafting (Review). Cochrane Database of Systematic Reviews 2007, Issue 1. DOI: 10.1002y14651858.CD004472.pub2

15. Theologou T, Bashir M, Rengarajan A, Khan $\mathrm{O}$, Spyt, Richens D, et al. preoperative intraaortic balloon pumps in patients undergoing coronary artery bypass grafting .cochrane Database Syst Rev.2011,Art.No.CD004472 .

16. Dyub AM,Whitlock RP,Abouzahr LL,Cina CS. preoperative intra-aortic balloon pumps in patients undergoing coronary artery bypass grafting: systematic review and metaanalysis.J Card Surg.2008,23:79-86.

17. Greco T, Zangrillo A, Biondi-Zoccai G, Landdoni G. Meta-analysis: pitfalls and hints.Heartlung vessel.2013, 5:219-25.

18. Holmann WL, Li Q, Kiefe C, McGiffin DC, Peterson ED, Allman RM, Nielsen VG, Pacifico AD. Prophylactic value of preincision intra-aortic balloon pump: analysis of a statewide experience. $\mathrm{J}$ Thorac Card Surg 2000;120:1112-1119.

19. Etienne PY, Papadatos S, Glineur D, Mairy Y, El Khoury E, Noirhomme P, El Khoury G. Reduced mortality in high-risk coronary patient operated off pump with preoperative intraaortic balloon counterpulsation. Ann Thorac Surg 2007; 84:498-502.

20. Rydén L, Sartipy U, Evans M, Holzmann MJ. Acute kidney injury after coronary artery bypass grafting and long-term risk of endstage renal disease. Circulation 2014; 130:2005-201.

21. Topkara VK, Cheema FH, Kesavaramanujam S, Mercando ML, Cheema AF, Namerow PB, et al. Coronary artery bypass grafting in patients with low ejection fraction. Circulation 2005; 112:I344-I350.

22. Qiu Z, Chen X, Xu M, Jiang Y, Xiao L, Liu $\mathrm{L}$, et al. Evaluation of preoperative intraaortic balloon pump in coronary patients with severe left ventricular dysfunction undergoing $\mathrm{OPCAB}$ surgery: early and mid- 
term outcomes. J Cardiothorac Surg 2009; 4:39.

23. Bedi HS, Sohal CS, Sengar BS. Elective preoperative use of intra-aortic balloon counterpulsation in high risk group of coronary artery disease patients to facilitate off pump surgery. Indian $\mathbf{J}$ Thorac Cardiovasc Surg 2007; 23:128-133.

24. Michel Pompeu BO, Ferraza PE, Escobara RR, Martinsa WN, Nunesa EO, Vasconcelosa FP, Limaa RC. Prophylactic intra-aortic balloon pump in high-risk patients undergoing coronary artery bypass surgery: a meta-analysis of randomized controlled trials. Coron Artery Dis 2012; 23:480-486.
25. Khira AW, Priceb S, Heneinc MY, Parkera KH, Pepperb JR. Intra-aortic balloon pumping: effects on left ventricular diastolic function. Eur J Cardiothorac Surg 2003; 24:277-282.

26. Elefteriades JA, Tolls G, Levi E, Mills LK, Zaret BL. Coronary artery bypass grafting in severe left ventricular dysfunction: excellent survival with improved ejection fraction and functional status. JACC 1993; 22:1411-1417.

27. Micelli A, Fiorani B, Danesi TH, Melina G, Sinatra R. Prophylactic intraaortic balloon pump in high-risk patients undergoing coronary artery bypass grafting: a propensity score analysis. Interact Cardiovasc Thorac Surg 2009; 9:291-295 